ECCOMAS

Proceedia
COMPDYN 2021

$8^{\text {th }}$ ECCOMAS Thematic Conference on Computational Methods in Structural Dynamics and Earthquake Engineering M. Papadrakakis, M. Fragiadakis (eds.)

\title{
APPLICATION OF THE EMPIRICAL PREDICTIVE DAMAGE MODEL OF HISTORICAL CHURCHES
}

\author{
C. Canuti ${ }^{1}$, M. Morici ${ }^{1}$, A. Dall'Asta ${ }^{1}$, G. Leoni ${ }^{1}$ \\ ${ }^{1}$ SAAD, University of Camerino \\ Viale della Rimembranza 9, 63100, Ascoli Piceno, Italy \\ \{claudia.canuti, michele.morici, andrea.dallasta, graziano.leoni\}@unicam.it
}

\begin{abstract}
Strong seismic events are the main cause of serious damage to cultural heritage, especially to historical churches characterized by a lack of efficient resisting mechanisms and by high vulnerability due to their structural systems peculiarities. Their poor seismic performance is demonstrated by the recurrence of specific seismic damage mechanisms. In this paper, an empirical probabilistic damage predictive model recently presented in the literature is used to provide a scenario dependent risk assessment in a seismic prone area in Italy. In this response model, the damage is expressed by a continuous index and the seismic action is described by a scalar intensity measure. For the illustrative case study, a sample of churches falling into a limited area of Marche Region, hit by the Central Italy 2016 seismic sequence, has been chosen. The sample includes all the historical churches belonging to the Archdiocese of Camerino-San Severino. The damage scenario following a seismic event of magnitude 5.8, generated by the Camerino fault, has been evaluated to illustrate the capability of this model in the prediction of post-earthquake situation. Risk maps obtained by means of the method presented in the paper, can provide a notable support to the organization of post-event emergency actions and to the planning of preventive actions for the risk mitigation.
\end{abstract}

Keywords: Historical churches; Seismic damage; Predictive empirical model; Shear-wave velocity.

ISSN:2623-3347 (C) 2021 The Authors. Published by Eccomas Proceedia.

Peer-review under responsibility of the organizing committee of COMPDYN 2021.

doi: $10.7712 / 120121.8663 .18917$ 


\section{INTRODUCTION}

The Italian territory is popular for its high number of historical churches constituting a very dominant part of the cultural heritage for the country. Unfortunately, most of the Italian territory is characterized by high seismicity and the effects of seismic events on the cultural heritage may be destructive, as demonstrated over the last years by seismic sequences, such as Irpinia earthquake (1980), Umbria Marche earthquake (1997), Molise earthquake (2002), L'Aquila earthquake (2009), Emilia Romagna earthquake (2012), Central Italy seismic sequence (2016).

Churches are characterized by structural and typological vulnerabilities higher than vulnerabilities of ordinary masonry buildings [1]. This bad seismic performance is caused by specific architectural configurations, such as large halls, absence of internal diaphragms, and presence of vaults and arches.

Studies carried out after seismic events, highlighted that the seismic response of churches is featured by a set of macro-elements, such as façade, transept, nave, apse, characterized by independent dynamic behaviors [2]; this is also confirmed by different analytical studies on the vulnerability assessment of single churches (e.g. [3-5]) and of groups of churches (e.g. [6-8]). In addition, the analysis of the observed damage after past seismic events, such as the UmbriaMarche 1997 earthquake [9-11], the Molise 2002 earthquake [12], L'Aquila 2009 earthquake [13-15], the Emilia 2012 earthquake [16,17], and Central Italy 2016 seismic sequence [18-23] demonstrated that damage mechanisms have constant characteristics, in spite of the uniqueness of each structure.

Starting from the damage observed after the seismic events, it is possible to define empirical predictive models relating damage with intensity measure. In literature, studies on this topic provided statistical analyses of the damages and models based on a discrete description of damage (damage limit states) [10, 13, 15, 18, 21, 23, 24, 25, 26].

Moreover, thanks to the enhancement of the seismographic network in recent years, recorded ground motions allow to develop more accurate relationships between ground motion intensity measure and observed damage. Indeed, recent works avoided the approximate description provided by macro-seismic scales and preferred a description based on objective measures of the ground motion, such as the Peak Ground Acceleration (PGA) [18, 21, 23, 26].

A probabilistic response model based on the analysis of data coming from post-earthquake surveys of historical churches has been defined in [27]. This empirical probabilistic damage model relates the measure of the ground motion intensity to the overall damage index, defined in a continuous range.

In this paper, an application of this predictive probabilistic damage model has been developed, considering a strong event generated by the main local seismogenetic source that struck 514 historical churches (Archdiocese of Camerino-San Severino) located in this seismic prone area. A damage scenario following an event of magnitude 5.8 generated by the Camerino fault has been considered and the intensity measure at the site of each church has been evaluated using the Ground Motion Prediction Equations of Sabetta and Pugliese [28]. In addition, the effects of local site amplification due to soil type is taken into account by means of the specific values of the time-averaged shear-wave velocity $\mathrm{V}_{\mathrm{S}, 30}$. The application depicts the potentialities of the model in the prediction of post-earthquake damage scenarios model, and the potential use of this risk assessment in the decision-making process by simulating a problem often arising in the post-event emergency phase, regarding the selection of those historical churches that may have suffered the highest damage levels. 


\section{EMPIRICAL DAMAGE PROBABILISTIC MODEL}

In this section, a brief introduction of the damage probabilistic model proposed by Morici et al. [27] and used in the following, is reported.

The model assumes that the damage index is a continuous random variable $D$, and the values $d$ are in the domain [0,1] while the seismic intensity is described by a positive scalar random variable $I$, in the domain $i \in(0, \infty)$. The boundary value $d=0$ represents the case of marginal damage while $d=1$ represents the case of collapsed church.

The probability to observe a damage level lower than an assigned value $d$, given the seismic intensity, defines the system response, described by the following Cumulative Density Function $(\mathrm{CDF})$

$$
F_{D \mid I}(d \mid i)=P[D<d \mid i]
$$

where $d \in[0,1]$. The conditional CDF of damage, given $i$, can be expressed in the form:

$$
F_{D \mid I}(d \mid i)=F_{0}(i) H(d)+\left(1-F_{0}(i)-F_{1}(i)\right) F_{D \mid I}^{*}(d \mid i)+F_{1}(i) H(d-1)
$$

since the expected conditional Probability Density Function (PDF) is expressed by a continuous function in the open interval $(0,1)$, and discontinuities are awaited at the boundaries $d=0$ (no damage) and $d=1$ (collapse).

In Equation 2, $F_{0}(i)$ provides the probability of observing $d=0, F_{1}(i)$ the probability of observing a damage $d=1$, and the function $F_{D \mid I}^{*}\left(d \mid i ; \boldsymbol{\Theta}_{d}\right)$ is a conditional CDF describing the distribution of damage probability for the range $0<d<1 . H(x)$ is the Heaviside step function, such that $H(x)=1$ for $x \geq 0$ and it is 0 elsewhere.

The associated conditional PDF has the form

$$
f_{D \mid I}(d \mid i)=F_{0}(i) \delta(d)+\left(1-F_{0}(i)-F_{1}(i)\right) f_{D \mid I}^{*}(d \mid i)+F_{1}(i) \delta(d-1)
$$

where $\delta$ is the delta Dirac function that expresses the derivative of the Heaviside function, while $f_{D \mid I}^{*}(d \mid i)$ is the derivative of $F_{D \mid I}^{*}(d \mid i)$ with respect to $d$. Figure 1 shows the conditional CDF $F_{D \mid I}(d \mid i)$ and PDF $f_{D \mid I}(d \mid i)$ adopted in the model.

The functions $F_{0}\left(i ; \boldsymbol{\Theta}_{0}\right)$ and $F_{1}\left(i ; \boldsymbol{\Theta}_{1}\right)$ are selected from the exponential family according with the available data and model discussed in [27]. In particular, the functions assume the forms $F_{0}(i)=e^{-6.32 i}$ and $F_{1}(i)=1-e^{-0.076 i}$. The conditional PDF $f_{D \mid I}^{*}\left(d \mid i ; \boldsymbol{\Theta}_{d}\right)$ consists of a combination of two Exponential Distribution Functions (EDF), $f_{D \mid I}^{*}(d \mid i)=\frac{1}{A(i)}\left(e^{-(4.9111-9.2474 i) d}-e^{-(4.9111-9.2474 i)}\right)\left(e^{-(-4.5176+12.4867 i)(1-d)}-e^{-(-4.5176+12.4867 i)}\right)$ where the term $A(i)$ is a normalization coefficient $A(i)=\int_{0}^{1} f_{D \mid I}^{*}(d \mid i) d d$. Finally, in the model, the measurement of the seismic intensity is described by means of the Peak Ground Acceleration (PGA). 


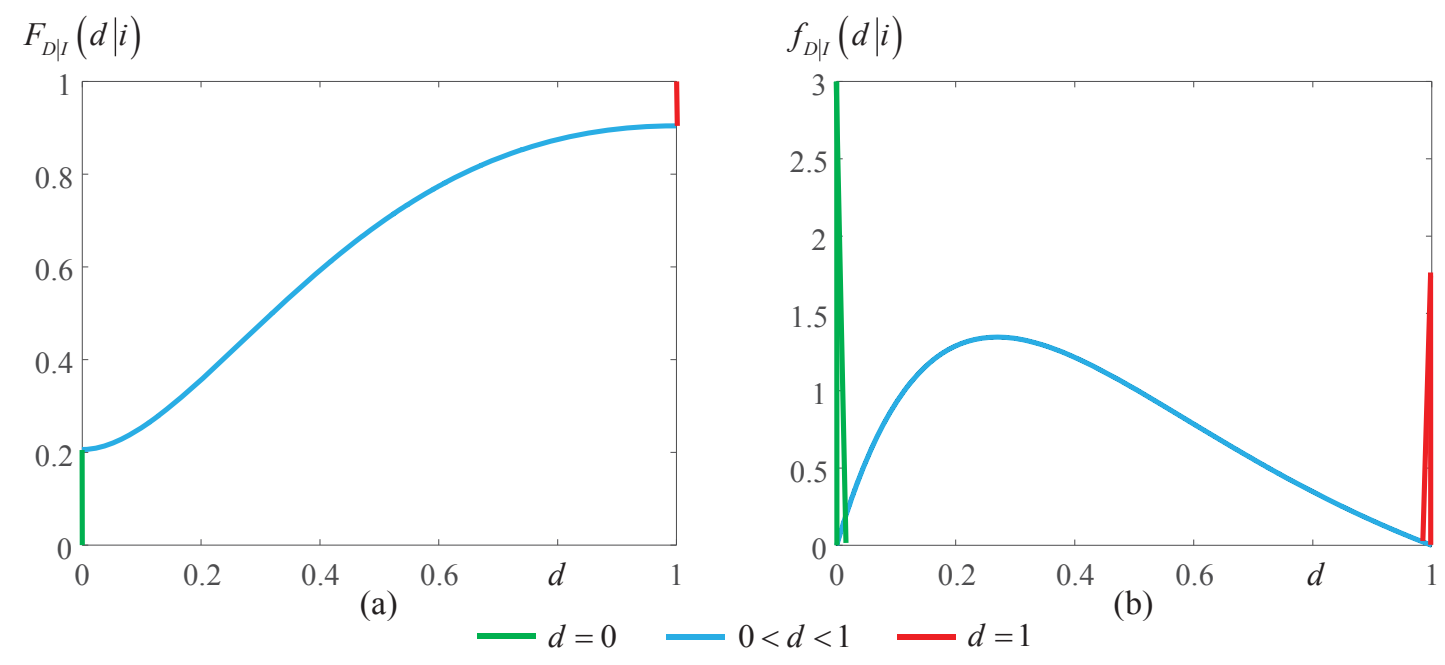

Figure 1: (a) Conditional CDF and (b) conditional PDF assumed in the [27] model.

\section{APPLICATION OF THE PROBABILISTIC DAMAGE MODEL}

\subsection{Seismic scenario}

In this paragraph, the evaluation of a damage scenario is presented, the Camerino fault has been considered as the seismic source and the damage expected in the set of historical churches belonging to Archdiocese of Camerino-San Severino, has been evaluated.

The Fault is located to a depth of 9-15 km (Figure $2 \mathrm{~b}$ ) and it is characterized by a potential magnitude $\mathrm{Mw}=5.8$, testified by the seismic event of 1799 that had a complex, and probably multiple, source that produced two separate areas of maximum damage [29]. The fault belongs to the Central Apennines fault system, where the active faults consist of arrays of distinct overlapping segments which may be unconnected or linked into a single continuous fault surface [30] as illustrated in Figure 2c. In addition, unconnected adjacent faults may interact each other through their stress fields, activating different earthquake sequences [30]. However, according with [31], it is possible to assume that the surface faults, belonging to each seismogenic zone responsible for generating single seismic events with multiple ruptures, are the surface manifestations of earthquake-related deformation.

Figure $2 \mathrm{a}$ reports the geographic location of Camerino fault, and Figure $2 \mathrm{~b}$ shows the distribution of the historical and recent seismic activity of the region and the areas mainly damaged after the event of 1799, identified with light blue rectangles [29]. Finally, Figure 2c displays the Central Apennines Fault System where measured active surface faults and related deep seismogenic structures are also shown [30].

The distribution of intensity measure $f_{I}(i)$ in terms of PGA, given the epicentral distance $r$ and the magnitude $M$, is evaluated by using Ambraseys et al. Ground Motion Prediction Equation (GMPE) [28] that assumes the form

$$
\log _{10}(I)=C_{1}+C_{2} M_{S}+C_{4} \log _{10} \rho+C_{A} S_{A}+C_{S} S_{S}+\varepsilon(\sigma)
$$

where $\varepsilon(\sigma)$ is a 0 -mean Gaussian random variable with standard deviation $\sigma$ that represent the inter-event residual, $S_{A}$ and $S_{S}$ are dummy variables depending on superficial soil category (rock, stiff, soft and very soft soil), $\rho=\sqrt{r^{2}+h_{0}^{2}}$ contains the epicentral distance $r$ and the fictitious depth $h$, and $C_{1}, C_{2}, C_{4}, C_{A}, C_{S}$ are the model constants. 


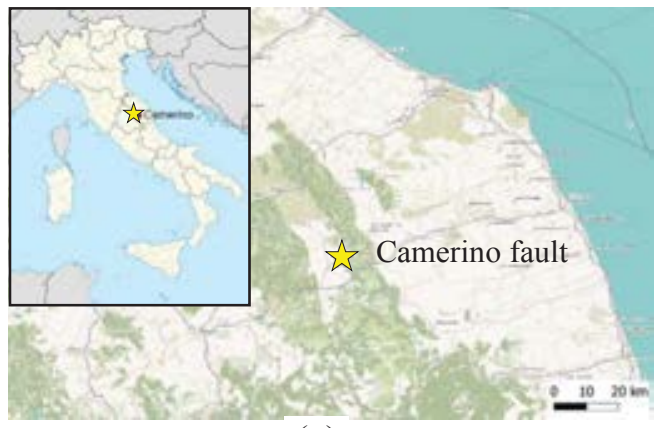

(a)

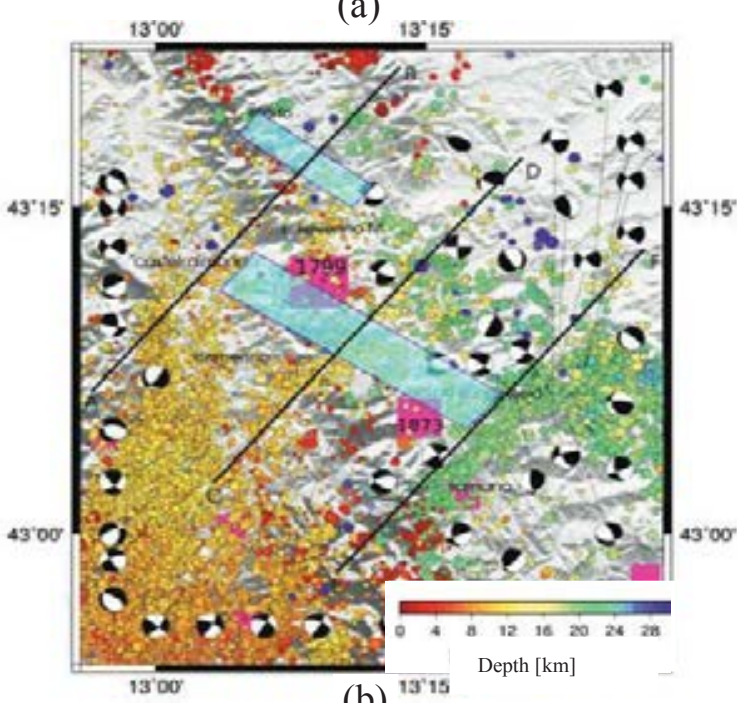

(b) ${ }^{13} 15$

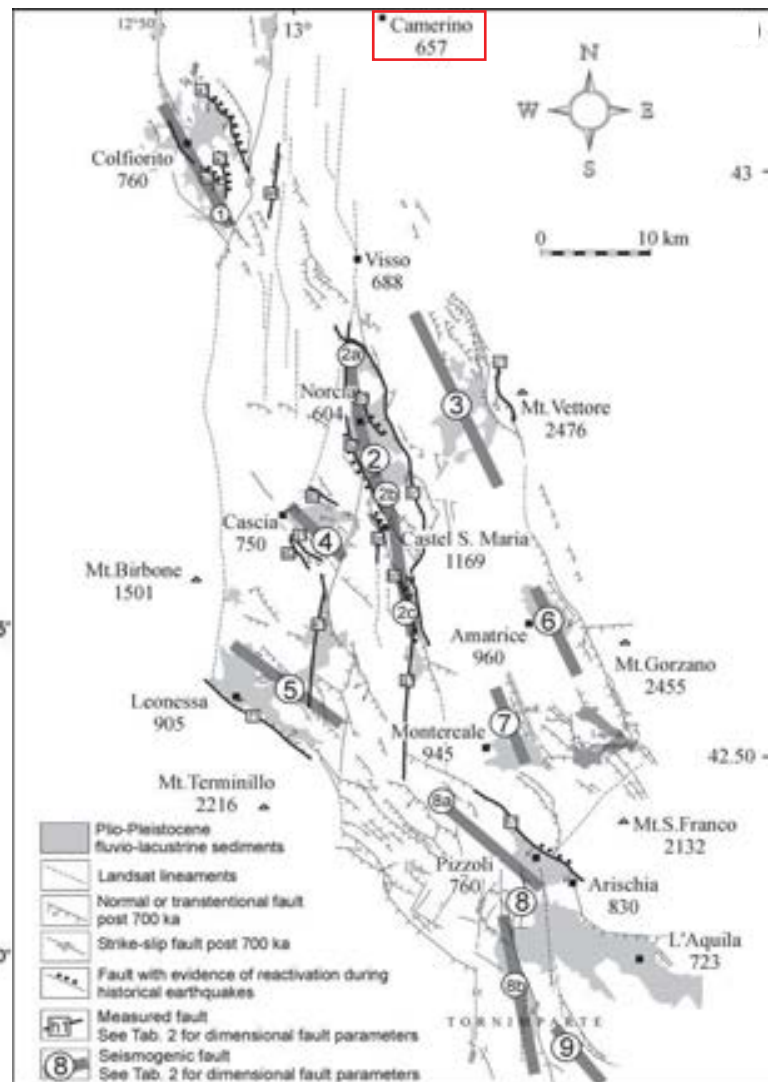

(c)

Figure 2: (a) Geographic location of Camerino fault; (b) Distribution of the historical and recent seismicity of the area with the areas mainly damaged after the 1799 earthquake [29]; (c) the Central Apennines Fault System [30].

In this study, parameters of the Eq. (4) are evaluated from the work [28] and the following values are assumed: $C_{1}=-1.48, C_{2}=0.266, C_{4}=-0.922, C_{A}=0.117, C_{S}=0.124$ and $h_{0}=3.5$, while the standard deviation of $\varepsilon$ is equal to 0.25 . The dummy variables $S_{A}$ and $S_{S}$ refer to the site classification: for $\mathrm{V}_{\mathrm{S}, 30}<180 \mathrm{~m} / \mathrm{s}, S_{A}=0$ and $S_{S}=1$ (very soft soil), for $180 \mathrm{~m} / \mathrm{s} \leq \mathrm{V}_{\mathrm{S}, 30}<360 \mathrm{~m} / \mathrm{s}, S_{A}=0$ and $S_{S}=1$ (soft soil), for $360 \mathrm{~m} / \mathrm{s} \leq \mathrm{V}_{\mathrm{S}, 30}<750 \mathrm{~m} / \mathrm{s}, S_{A}=1$ and $S_{S}=0$ (stiff soil), and for $\mathrm{V}_{\mathrm{S}, 30}>750 \mathrm{~m} / \mathrm{s}, S_{A}=0$ and $S_{S}=0$ (rock).

The possible effects of local amplification caused by the local geology of the site and identified by the category of soil, are evaluated by means of the $\mathrm{V}_{\mathrm{S}, 30}$ parameter. The $\mathrm{V}_{\mathrm{S}, 30}$ value represents the time-averaged shear-wave velocity to $30 \mathrm{~m}$ depth, and it is representative of the soil deformability. The specific $\mathrm{V}_{\mathrm{S}, 30}$ of each church site has been selected on the basis of the studies of USGS [32-33].

Figure 3 shows the distribution of the $V_{\mathrm{S}, 30}$ at each church site derived from the USGS $\mathrm{V}_{\mathrm{S}, 30}$ Map Viewer. The table reports the number of historical churches placed in sites with different range of $\mathrm{V}_{\mathrm{S}, 30}$. Figure 4a shows the distribution of the mean value of intensity measure for each $k^{\text {th }}$ church $(k=1, . ., 514)$ where the index has been assigned after the churches have been ordered according to the expected intensity measure. Figure $4 \mathrm{~b}$ reports the PDF of the intensity $f_{I}^{k}(i)$ expected at each $k^{\text {th }}$ church, considering their epicentral distance and the relevant $\mathrm{V}_{\mathrm{S}, 30}$. 
It can be observed that the seismic intensity is mainly related to the epicentral distance while the local amplification related to $\mathrm{V}_{\mathrm{S}, 30}$ plays a secondary role.

The distribution of damage can be evaluated by combining the damage model with the distribution of seismic intensity:

$$
F_{D}^{k}(d)=\int_{\mathfrak{R}^{+}} F_{D}(d) f_{I}^{k}(i) d i
$$

where $F_{D}^{k}(d)$ is the CDF of the damage relative to the $k^{\text {th }}$ church.

Figure 5 reports the $\operatorname{CDF} F_{D}^{k}(d)$ and the related PDF $f_{D}^{k}(d)$ of damage for each church. It can be noticed that the probability of observing undamaged churches $(d=0)$ increases with the reduction of the seismic intensity.

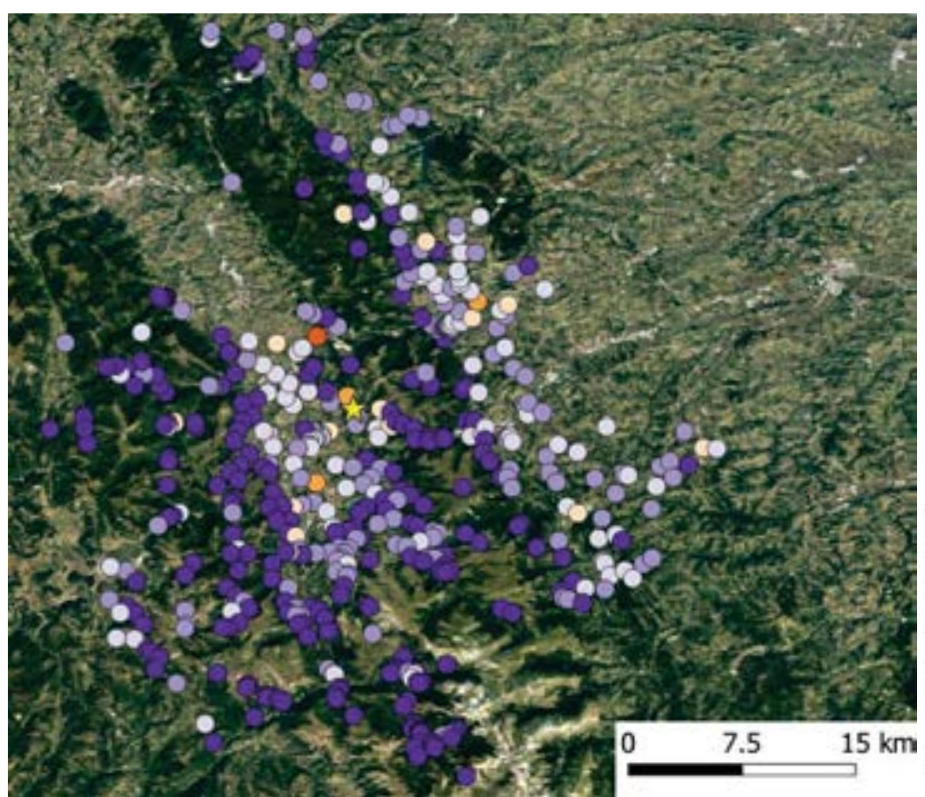

$$
\begin{aligned}
& \text { Churches location } \\
& \text { is Camerino fault } \\
& V_{s, 30}\left[\mathrm{~m} / \mathrm{s}^{2}\right] \\
& 0<V_{s, 30} \leq 240 \\
& 240<V_{s, 30} \leq 300 \\
& 300<V_{s, 30} \leq 360 \\
& 360<V_{s, 30} \leq 490 \\
& 490<V_{s, 30} \leq 600
\end{aligned}
$$

\begin{tabular}{|c|c|}
\hline Ranges of $\mathrm{V}_{\mathrm{x}, 50}$ & $\mathbf{N}^{\circ}$ of churches \\
\hline $0<\mathrm{V}_{5} \leq 0 \leq 240$ & 1 \\
\hline $240<\mathrm{V}_{\leq 30} \leq 300$ & 3 \\
\hline $300<\mathrm{V}_{5,30} \leq 360$ & 13 \\
\hline $360<\mathrm{V}_{530} \leq 490$ & 114 \\
\hline $490<\mathrm{V}_{530} \leq 600$ & 142 \\
\hline $600<\mathrm{V}_{5,30} \leq 760$ & 241 \\
\hline
\end{tabular}

Figure 3: $\mathrm{V}_{\mathrm{S}, 30}$ distribution over the territory for the churches of the Archdiocese of Camerino San-Severino.

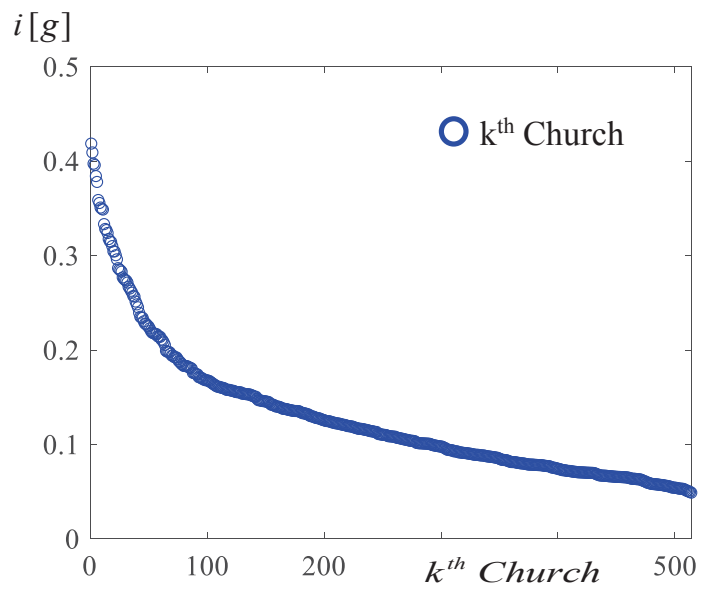

(a)

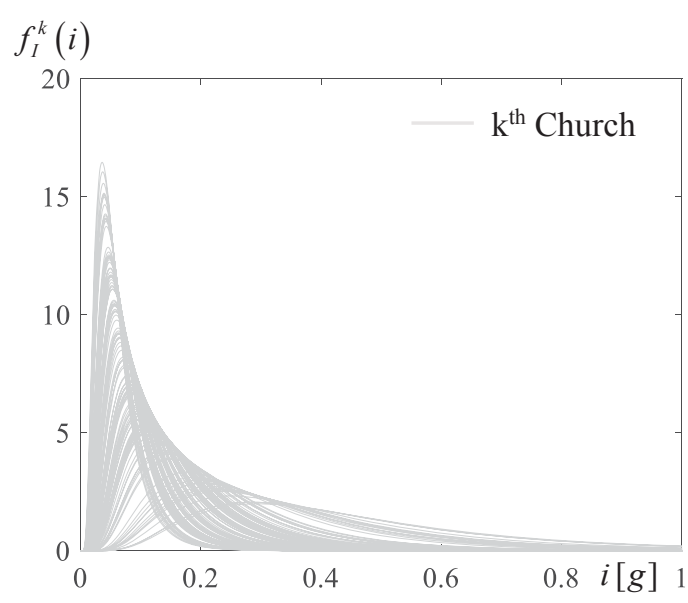

(b)

Figure 4: (a) mean expected intensity measure of seismic hazard; (b) distribution of intensity given epicentral distance 


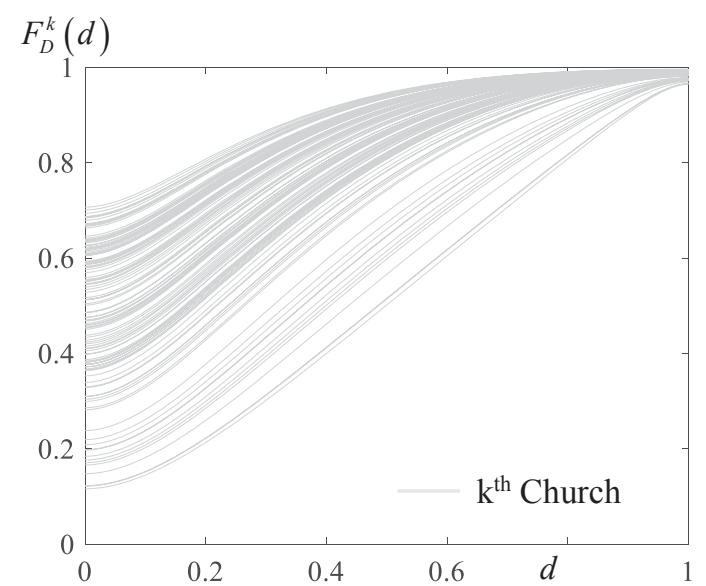

(a)

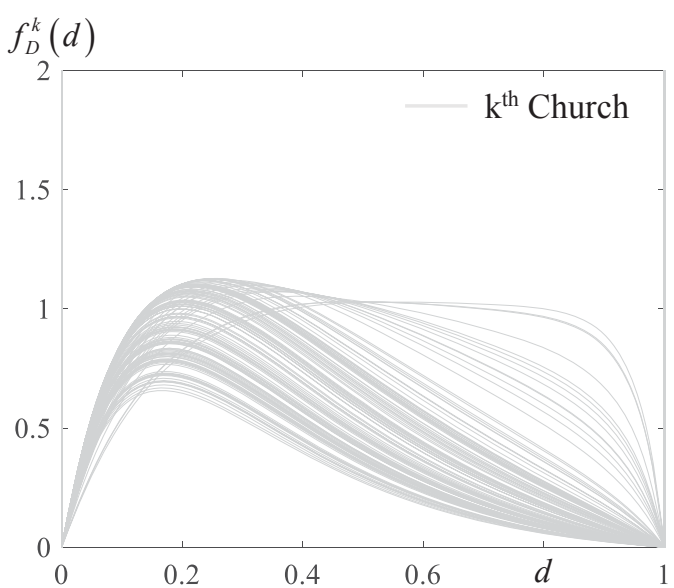

(b)

Figure 5: Damage distribution given epicentral distance and $\mathrm{V}_{\mathrm{S}, 30}$ : (a) $\operatorname{CDF} F_{D}^{k}(d)$ and (b) $\operatorname{PDF} f_{D}^{k}(d)$.

Figure 6a shows the distribution of the mean damage $\mu_{D}^{k}$ and $\mu_{D}^{k} \pm \sigma_{D}^{k}$ where $\sigma_{D}^{k}$ is the standard deviation of each church, over the seismic intensity. Figure $6 \mathrm{~b}$ reports the $25^{\text {nd }}$ percentile, the median, and the $75^{\text {nd }}$ percentile for the damage of each church. Moreover, also the extreme values corresponding to the 5 and 95 percentiles are reported.

Finally, Figure 7 describes the overall damage scenario expected for the churches of the Archdiocese of Camerino- San Severino, by combining results obtained from the damage models with the location of the historical churches. In details, the expected mean value of $d$ of each church is illustrated by a red color scale and the table reports the number of historical churches suffering of different levels of damage.

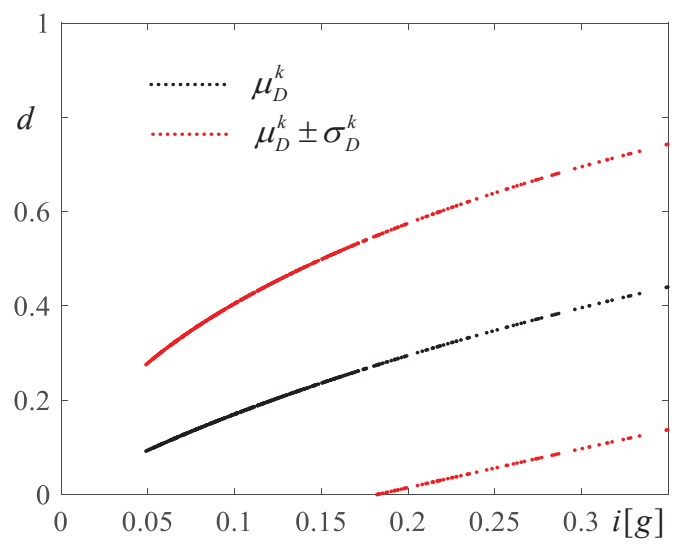

(a)

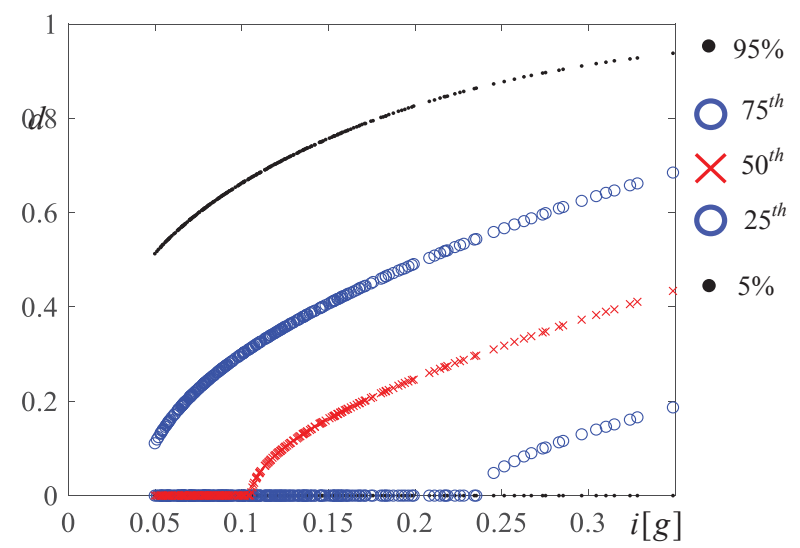

(b)

Figure 6: Damage distribution given seismic intensity (a) mean damage and (b) percentiles of damage.

\subsection{Decision making}

The damage scenario, that represents the combination between the response model and the seismic hazard, may be used to take decisions concerning specific actions oriented to mitigate the seismic risk or to improve the emergency management.

In particular, the following decision problem concerning the emergency management is considered to illustrate the potentialities of the methodology presented for the risk assessment. 


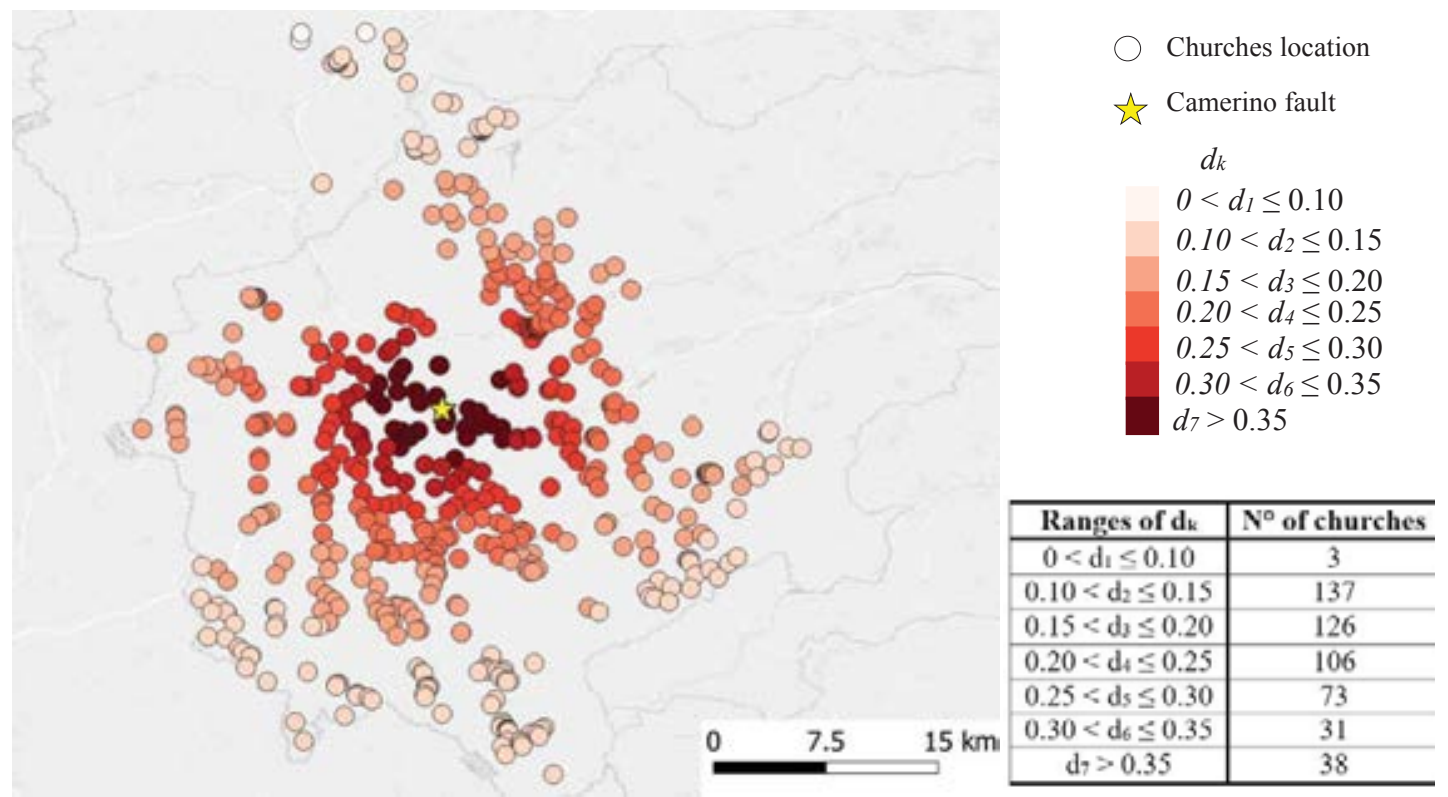

Figure 7: Damage distribution over the territory for the churches of the Archdiocese of Camerino San-Severino.

After a seismic event, the total set of churches must be divided into two subsets where, in one case, a damage larger than an assigned threshold is expected while, in the other case a damage lower than this threshold is expected. The sub-division is based on the location of the churches. A percentage of misclassification is expected in both the subsets, and the study wants to divide the total set in such a way that the misclassification is minimized.

The churches have been classified considering the median value of the seismic intensity at their site. This is an information usually available after the seismic event and it depends on the church location only, so that a classification based on the geographical position is possible. The median value of the intensity can be evaluated by Eq. 4, neglecting the last term related to the uncertainties. A threshold $i_{0}$ is chosen to divide the total set into two subsets where the median value of the expected intensity is lower or higher than $i_{0}$.

The number of churches falling in the set where the median value of the intensity is lower than $i_{0}$ is denoted by $n_{0}\left(i_{0}\right)$. It can be concluded that the total probability to observe the event $E_{0}$ in this subset can be obtained by combining the probability to observe a damage lower than the threshold $\bar{d}$ with the probability of selecting a church in this subset

$$
P_{E}\left[E_{0} \mid i_{0}\right]=\frac{1}{n_{0}\left(i_{0}\right)} \sum_{0}^{n_{0}\left(i_{0}\right)} \int_{0}^{\bar{d}} f_{D}^{k}(d) d d
$$

while $P_{E}\left[E_{1} \mid i_{0}\right]=1-P_{E}\left[E_{0} \mid i_{0}\right]$ provides the probability to observe the event $E_{1}$ within the same subset.

In this analysis, two threshold damage values $\bar{d}=0.1$ and $\bar{d}=0.2$ have been considered. Figure 8 shows the trends of $P_{E}\left[E_{0} \mid i_{0}\right]$ and $P_{E}\left[E_{1} \mid i_{0}\right]$, the value of seismic intensity $i_{0}$ that minimizes the probability of misprediction is highlighted by the dashed line. The optimal values of the seismic intensities $i_{0}$ are $0.1240 \mathrm{~g}$ for $\bar{d}=0.1$, and $0.1708 \mathrm{~g}$ for $\bar{d}=0.2$, respectively. 

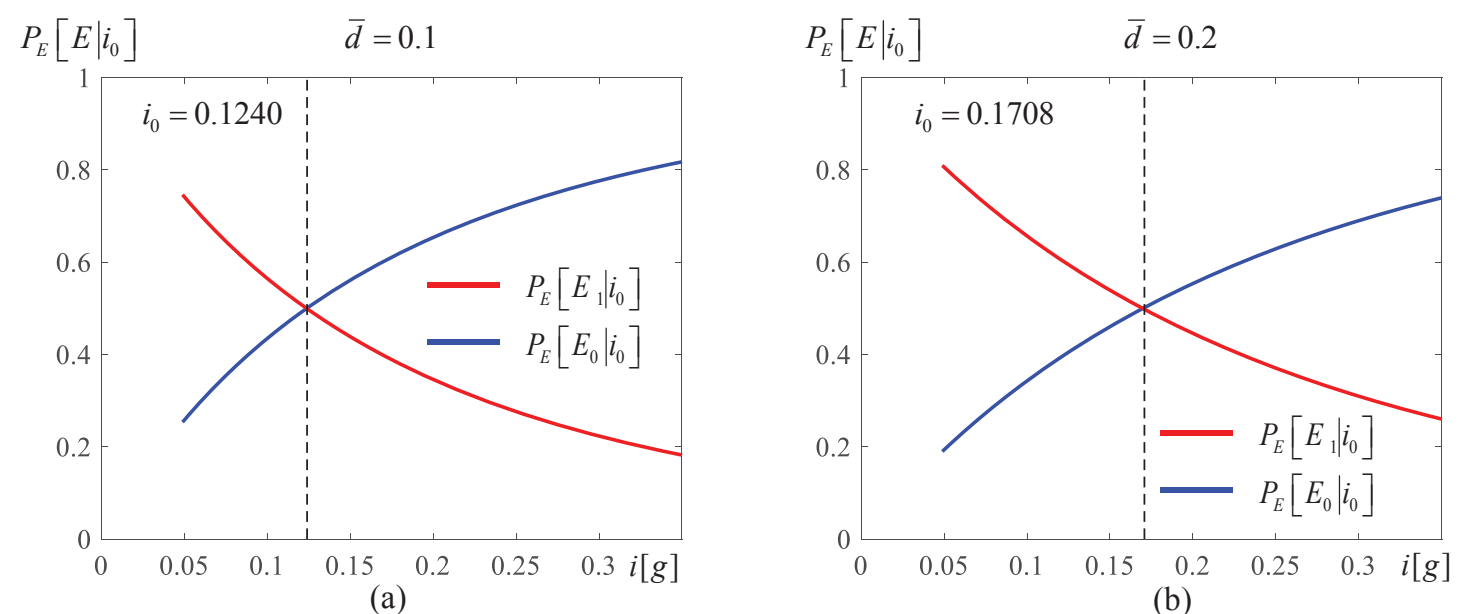

(b)

Figure 8: Probability of the two events $E_{0}$ and $E_{1}$ for different threshold of the intensity, for $\bar{d}=0.1$ and

$$
\bar{d}=0.2 \text {. }
$$

\section{CONCLUSIONS}

An illustrative application, starting from the empirical predictive model for the seismic damage of historical churches recently presented in the technical literature, has been proposed in this paper. In this empirical probabilistic model, the damage is expressed by a continuous index and the seismic action is described by a scalar intensity measure. A sample of churches falling into a limited area of Marche Region hit by the Central Italy 2016 seismic sequence has been chosen for the illustrative case study.

A specific scenario has been considered, assuming a seismic event of magnitude 5.8 generated by the Camerino fault. The probability distribution of damage has been evaluated for 514 historical churches, according to their locations and the mechanical properties of the soil. Results have been discussed and risk maps have been presented.

Potential use of this risk assessment methodology in the decision-making process has been illustrated by simulating a problem often arising in the post-event emergency phase: the selection of those historical churches that may have suffered the highest damage levels.

\section{ACKNOWLEDGMENTS}

The authors acknowledge the sponsorship of the Italian Civil Protection, through the RELUIS Project - WP4: MAppe di Rischio e Scenari di danno sismico (MARS) (2019).

\section{REFERENCES}

[1] L. Sorrentino, S. Cattari, F. Da Porto, G. Magenes, A. Penna, Seismic behaviour of ordinary masonry buildings during the 2016 central Italy earthquakes. Bulletin of Earthquake Engineering https://doi: 10.1007/s10518-018-0370-4, 2019.

[2] F. Doglioni, A. Moretti, V. Petrini, P. Angeletti, Le Chiese e il Terremoti: Dalla Vulnerabilità Constatata nel Terremoto del Friuli al Miglioramento Antisismico nel Restauro, Verso una Politica di Prevenzione. Edizioni Lint, Trieste, Italy, 1994.

[3] E. Mele, A. De Luca, A. Giordano, Modelling and analysis of a basilica under earthquake loading. Journal of Cultural Heritage. 4 (4):355-67. https://doi:10.1016/j.culher.2003.03.002, 2003. 
[4] F. Casarin, C. Modena, Seismic assessment of complex historical buildings: application to Reggio Emilia Cathedral, Italy. International Journal of Architectural Heritage. 2 (3):30427. https://doi: 10.1080/15583050802063659, 2008.

[5] G. De Matteis, F.M. Mazzolani, The Fossanova Church: seismic vulnerability assessment by numeric and physical testing. International Journal of Architectural Heritage. 4 (3):222-45. https://doi: 10.1080/15583050903078903, 2010.

[6] M. D'Amato, M. Laterza, D. Diaz Fuentes, Simplified seismic analyses of ancient churches in Matera's Landscape. International Journal of Architectural Heritage, Article Published on line, 1-20, https://doi: 10.1080/ 15583058.2018.1511000, 2018.

[7] F. Fabbrocino, G. Vaiano, A. Formisano, Parametric analysis on local collapse mechanisms of masonry churches. Proceedings of AIP Conference, Rhodes, Greece, 2018.

[8] D.D. Fuente, M. D’Amato, M. Laterza, Seismic vulnerability and risk assessment of historic constructions: the case of masonry and adobe churches in Italy and Chile. 11th International Conference on Structural Analysis of Historical Constructions, Cusco, Perù, pp. $1127-37,2019$.

[9] S. Lagomarsino, S. Podestà, Seismic vulnerability of ancient churches I. Damage assessment and emergency. Earthquake Spectra. 20 (2):377-94. https://doi:10.1193/1.1737735, 2004a.

[10] S. Lagomarsino, S. Podestà, Seismic vulnerability of ancient churches II. Statistical analysis of surveyed data and methods for risk analysis. Earthquake Spectra. 20 (2):395-412. https://doi:10.1193/1.1737736, 2004b.

[11] S. Giovinazzi, S. Lagomarsino, A macroseismic method for the vulnerability assessment of buildings. 13th World Conference on Earthquake Engineering, 2004.

[12] S. Lagomarsino, S. Podestà, Damage and vulnerability assessment of churches after the Molise earthquake 2002. Earthquake Spectra. 20(S1):S271-S283, 2004c.

[13] S. Lagomarsino, Damage assessment of churches after L'Aquila earthquake (2009), Bulletin of Earthquake Engineering. https://doi.org/10.1007/s10518-011-9307-x, 2012.

[14] F. Da Porto, B. Silva, C. Costa, C. Modena, Macro-Scale Analysis of Damage to Churches after Earthquake in Abruzzo (Italy) on April 6, 2009, Journal of Earthquake Engineering. 16:6, 739-758, https://doi: 10.1080/13632469.2012.685207, 2012.

[15] G. De Matteis, G. Brando, V. Corlito, Simplified Assessment of the Seismic Vulnerability of Churches After the 2009 L'Aquila Earthquake, Structural Analysis of Historical Constructions. Bullettin Earthquake Engineering. 17: 4909. https://doi.org/10.1007/s10518019-00656-7, 2019.

[16] M. Indirli, G. Marghella, A. Marzo, Damage and collapse mechanisms in churches during the Pianura Padana Emiliana earthquake. Energia Ambiente Innovazione. 11/2012; 4/5:6994, 2012.

[17] L. Sorrentino, L. Liberatore, L.D. Decanini, D. Liberatore, The performance of churches in the 2012 Emilia earthquakes. Bullettin of Earthquake Engineering. 12, 2299-2331, 2014.

[18] C. Canuti, S. Carbonari, A. Dall'Asta, L. Dezi, F. Gara, G. Leoni, M. Morici, E. Petrucci, A. Prota, A. Zona, Post-Earthquake Damage and Vulnerability Assessment of Churches in the Marche Region Struck by the 2016 Central Italy Seismic Sequence. International Journal of Architectural Heritage, https://doi: 10.1080/15583058.2019.1653403, 2019. 
[19] S. Carbonari, A. Dall'Asta, L. Dezi, F. Gara, G. Leoni, M. Morici, A. Prota, A. Zona, First analysis of data concerning damage occurred to churches of the Marche region following the 2016 central Italy earthquakes. Bollettino di Geofisica Teorica ed Applicata, 60 (2):183-96, 2019.

[20] A. Penna, C. Calderini, L. Sorrentino, C. Carocci, E. Cescatti, R. Sisti, A. Borri, C. Modena, A. Prota, Damage to churches in the 2016 central Italy earthquakes. Bulletin of Earthquake Engineering. https://doi: 10.1007/s10518-019-00594-4, 2019.

[21] E. Cescatti, P. Salzano, C. Casapulla, F. Ceroni, F. da Porto, A. Prota, Damages to masonry churches after 2016-2017 Central Italy seismic sequence and definition of fragility curves. Bullettin of Earthquake Engineering, https://doi: 10.1007/s10518-019-00729-7, 2019.

[22] M. Di Ludovico, G. De Martino, A. Santoro, A. Prota, G. Manfredi, C. Calderini, C. Carocci, F. Da Porto, A. Dall'Asta, S. De Santis, G. Fiorentino, A. Digrisolo, M. Dolce, C. Moroni, B. Ferracuti, D. Ferretti, F. Graziotti, A. Penna, A. Mannella, L. Sorrentino, Usability and damage assessment of public buildings and churches after the 2016 Central Italy earthquake. Earthquake Geotechnical Engineering for Protection and Development of Environment and Constructions. Volume: Silvestri \& Moraci (Eds), 2019.

[23] G. De Matteis, M. Zizi, Seismic Damage Prediction of Masonry Churches by a PGA-based Approach, International Journal of Architectural Heritage. 13:7, 1165-1179, https://doi: 10.1080/15583058.2019.1597215, 2019.

[24] S. Lagomarsino, On the vulnerability assessment of monumental buildings. Bulletin of Earthquake Engineering. 4. 445-463. 10.1007/s10518-006-9025-y, 2006.

[25] G. De Matteis, E. Criber, G. Brando, Damage Probability Matrices for Three-Nave Masonry Churches in Abruzzi After the 2009 L'Aquila Earthquake. International Journal of Architectural Heritage, 10:2-3, 120-145. http://dx.doi.org/10.1080/15583058.2015.1113340, 2016.

[26] L. Hofer, P. Zampieri, M.A. Zanini, F. Faleschini, C. Pellegrino, Seismic damage survey and empirical fragility curves for churches after the August 24, 2016 Central Italy earthquake. Soil Dynamics and Earthquake Engineering, 111, 98-109, 2018.

[27] M. Morici, C. Canuti, A. Dall'Asta, G. Leoni, Empirical predictive model for seismic damage of historical churches. Bulletin of Earthquake Engineering. doi:10.1007/s10518-02000903-2, 2020.

[28] N.N Ambraseys, K. Simpson, A. Bommer, Prediction of horizontal response spectra in Europe. Earthquake Engineering \& Structural Dynamics, 25:4, 371-400, 1996.

[29] Quaderni di Geofisica, ISSN 1590-2595, Numero 138, In Italian, 2016

[30] E. Tondi, G. Cello, Spatiotemporal evolution of the Central Apennines fault system (Italy), Journal of Geodynamics, Volume 36, Issues 1-2, Pages 113-128, ISSN 0264-3707, https://doi.org/10.1016/S0264-3707(03)00043-7, 2003.

[31] E., Tondi, Geological analysis and seismic hazard in the Central Apennines. In: Cello, G., Tondi, E. (Eds.), The resolution of geological analysis and models for earthquake faulting studies. Journal of Geodynamics 29 (3-5), 517- 534, 2000.

[32] Vs30 Map Viewer: Topographic Slope as a Proxy for Seismic Site-Conditions (VS30) and Amplification around the Globe, Trevor I. Allen and David J. Wald, Website. https:// https://usgs.maps.arcgis.com. Accessed 15 March 2021 
[33] D. Heath, D.J. Wald, C.B. Worden, E.M. Thompson, G. Scmocyk, A Global Hybrid VS30 Map with a Topographic-Slope-Based Default and Regional Map Insets", Earthquake Spectra, vol. 36, 3: pp. 1570-1584, 2020. 